\title{
ADSORPTION OF METHYLENE BLUE ONTO CARBONS MADE OF RESIDUES FROM THE BIODIESEL INDUSTRY
}

\author{
D.A. LÁZARO ${ }^{1}$, C.L. CALDEIRA ${ }^{1}$, M.S.S. DANTAS ${ }^{1}$, M.B. MANSUR ${ }^{1}$, L.S. OLIVEIRA ${ }^{2}$ \& A.S. FRANCA ${ }^{2}$ \\ ${ }^{1}$ Department of Metallurgical and Materials Engineering, Universidade Federal de Minas Gerais, Brazil. \\ ${ }^{2}$ Department of Mechanical Engineering, Universidade Federal de Minas Gerais, Brazil.
}

\begin{abstract}
The performance of carbons produced from the cold-pressed cake of Raphanus sativus (L. var.), a residue from the biodiesel industry, was evaluated for the adsorption of methylene blue (MB) from synthetic aqueous solutions. The study has focused on the following three topics: (i) physical and textural characterization of the carbon, (ii) batch investigation of equilibrium and kinetics of MB adsorption at room temperature, and (iii) analysis of MB adsorption mechanism onto such carbonaceous structures. Regarding the first topic, carbon was characterized using several methods such as Brunauer-Emmett-Teller (BET), Barrett-Joyner-Halenda $(\mathrm{BJH})$, scanning electron microscopy (SEM), and Raman spectroscopy. A microporous carbon was found thus indicating that $\mathrm{MB}$ adsorption may occur predominantly at the surface of the carbon. Regarding the second topic, equilibrium tests revealed that Langmuir-based maximum MB uptake capacity was $19.8 \mathrm{mg} \mathrm{g}^{-1}$ and that MB kinetics onto carbon was best described by a pseudo second-order model. Data fitting analysis confirmed that MB adsorption onto such carbons was predominantly superficial. And finally, regarding the third topic, MB adsorption may probably occur by bonding of monomer MB through the central nitrogen atom of its molecule and through sulfur atom while MB bonding through amino nitrogen atom does not seem probable. The study reveals that carbons made of $R$. sativus are suitable materials for the removal of dyes from aqueous solutions, mainly if finer fraction of carbons is used, because MB adsorption was found to be predominantly superficial. Keywords: adsorption equilibrium, adsorption kinetics, methylene blue, Raman spectroscopy.
\end{abstract}

\section{INTRODUCTION}

The recycling of water and the recovery of wastes constitute essential issues today worldwide. In such aspect, the use of waste materials for the removal of toxic species like synthetic dyes from textile wastewaters is twice advantageous and extremely important to allow the reuse of water and/ or the final discharge of effluents. It is well known that most of dyes are toxic, mutagenic, and carcinogenic even at low concentrations in water, so environmental regulations in most countries have made it mandatory to decolorize wastewaters prior to discharge in natural water streams. In fact, the use of a solid waste material to produce clean water for reuse is interesting not only due to environmental concerns but also due to the economical point of view.

Several methods have been developed to remove dyes from aqueous solutions in order to decrease their impact on the environment like adsorption, coagulation, ultrafiltration, photodegradation with ozone, chemical degradation, electrochemical flotation, and biodegradation [1-5]. The main drawback related to these technologies is that they generally lack the broad scope treatment efficiency required to simultaneously reduce the multitude of pollutants present in textile wastewater. Furthermore, for most of them, the capital and/or operating costs often become prohibitive when applied to the large-scale water treatment requirements of this type of industries.

As long as there is no universal method available for color removal from aqueous solutions, some technologies have been extensively investigated for the remediation of dyes using non-conventional low-cost sorbents based on waste materials generated by industrial and agricultural activities such as wheat, corn straw, olive stones, bagasse, birch wood, miscanthus, sunflower shell, pinecone, rapeseed, cotton residues, olive residues, pine rayed, eucalyptus maculata, sugar cane bagasse, and many others [6]. In fact, low-cost adsorbents prepared from agricultural and food wastes may be the most 
promising type of biomaterials that will lead to a globalized bio-based economy. The production and applicability of such sorbents has been several times proven economical and effective $[4,6]$.

In this context, the removal of methylene blue (MB) using carbons produced from the coldpressed cake of Raphanus sativus (L. var.), a residue from the biodiesel industry, was investigated in this work. The study has focused on the following three topics: (i) physical and textural characterization of the carbon, (ii) batch investigation of equilibrium and kinetics of MB adsorption at room temperature, and (iii) analysis of MB adsorption mechanism onto such carbonaceous structures.

\section{EXPERIMENTAL}

\subsection{Characterization of the carbon}

Details on the procedure used to prepare the carbon are given elsewhere [7]. Morphological analysis before and after carbonization procedure were carried out by scanning electron microscopy (SEM) using a JEOL microscopy (model JSM6360LV). Due to the non-conductive nature of the material, samples were covered with a thin layer of gold. The qualitative composition at surface of some particles was obtained by SEM coupled with X-ray energy dispersive spectrometry (EDS) using a Thermo Noran spectrometer (model Quest). Surface area, total pore volume, and average pore diameter were assessed by measuring $\mathrm{N}_{2}$ adsorption/desorption isotherms at $77 \mathrm{~K}$ of the adsorbents in an Autosorb-1 MP (Quantachrome). For such analysis, samples were outgassed at $473 \mathrm{~K}$ under vacuum for $3 \mathrm{~h}$. The specific surface area value was calculated according to the Brunauer-Emmett-Teller (BET) equation and pore parameters (pore volume and pore diameter) were evaluated based on Barrett-Joyner-Halenda (BJH) model.

\subsection{Batch adsorption tests: equilibrium and kinetics}

Batch adsorption experiments were performed in $250 \mathrm{~mL}$ agitated Erlenmeyer flasks (100 rpm) covered with aluminum foil to prevent photodegradation. In all sets of experiments, a pre-determined amount of carbon was thoroughly mixed with $100 \mathrm{~mL}$ of $\mathrm{MB}$ solution. Equilibrium tests lasted $72 \mathrm{~h}$ (adsorbent concentration $10 \mathrm{~g} \mathrm{~L}^{-1}$; initial $\mathrm{pH}=5$; particle size diameter $<0.425 \mathrm{~mm}$ ), while kinetics tests lasted from $15 \mathrm{~min}$ to $72 \mathrm{~h}$ with initial MB concentrations ranging from 100 to 500 $\mathrm{mg} \mathrm{L}^{-1}$. All tests were performed in duplicates. MB concentration was determined through spectroscopy in the visible region $(665 \mathrm{~nm})$ of $\mathrm{MB}$ solution samples after $0.25,0.5,1,2,6,11,35$, and $72 \mathrm{~h}$ of test.

\subsection{MB adsorption mechanism analysis tests}

Raman analysis was carried out in order to evaluate the structural change of the carbon due to the adsorption of MB. A Jobin-Yvon/Horiba Raman laser system (model Labran HR800) coupled with a transference optic microscopy was used. Samples of carbon (unloaded and MB-loaded samples) were analyzed under the following conditions: lens $100 \times$, laser power $<1 \mathrm{~mW}$, laser acquisition time $=20$ $\mathrm{s}$ (acquisitions $5 \times$ ), red laser wavelength $=632.8 \mathrm{~nm}$, analysis in two points $(1 \mu \mathrm{m})$. MB-loaded carbon samples were obtained by contacting MB solutions in $250 \mathrm{~mL}$ agitated Erlenmeyer flasks (100 rpm) at following conditions: initial $\mathrm{MB}$ concentration $=500 \mathrm{mg} \mathrm{L}^{-1}$; initial $\mathrm{pH}=5$; adsorbent dosage $=$ $10 \mathrm{~g} \mathrm{~L}^{-1}$; temperature $=25^{\circ} \mathrm{C}$; contact time $=72 \mathrm{~h}$. As it was not possible to get the Raman spectra for MB solutions in concentrations as those commonly used in the adsorption tests (an intense fluorescence was obtained probably due to the color of solution), the solid MB reagent was evaluated for 
comparative analysis under the following conditions: laser power $=0.08 \mathrm{~mW}$, wavelength $=632.8 \mathrm{~nm}$, laser acquisition time $=10 \mathrm{~s}$. Analytical MB, $15 \%$ hydrated (95\% purity, Labsynth, Brazil) was used to load carbon for Raman analysis.

\section{RESULTS AND DISCUSSION}

\subsection{Characterization of the carbon}

The carbon of $R$. sativus typically constitutes particles of homogeneous color, highly irregular shapes, and different sizes normally smaller than $1 \mathrm{~mm}$. They could be classified into fine and coarse fractions due to low mechanical resistance of the material. SEM micrographs at resolution of $3500 \times$ are shown in Fig. 1a for the raw material and in Fig. 1b for the carbon. As expected, an increase on the porosity of carbon due to carbonization was verified but it was not significant for the conditions studied. A qualitative composition given by EDS reveals that particles contain predominantly carbon, as well as phosphorous, calcium, magnesium, and potassium. Metals such as zinc and copper were found at very low quantities. The presence of oxygen was found to be quite low as well.

(a)

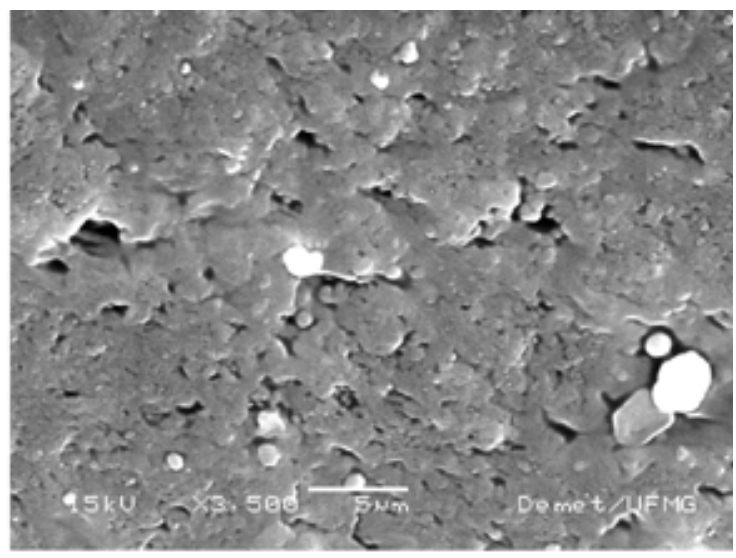

(b)

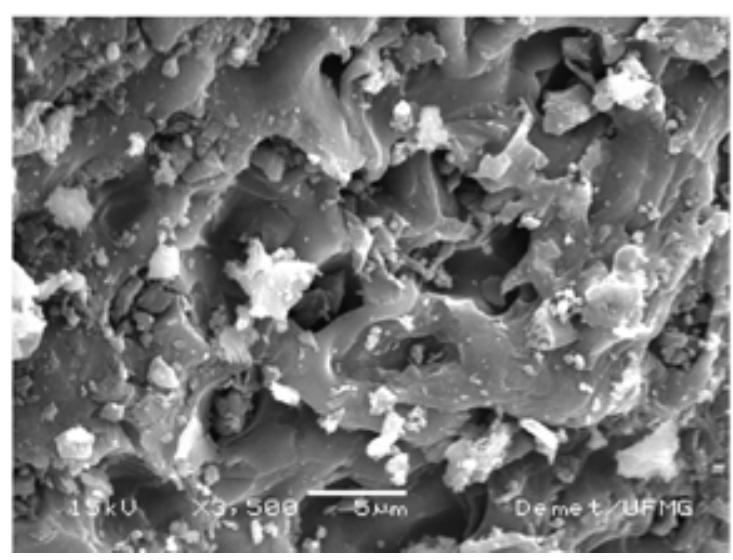

Figure 1: Surface aspect at SEM resolution of $3500 \times$ : (a) raw material and (b) carbon. 
The following properties of the carbon of $R$. sativus were estimated by $\mathrm{N}_{2}$ gas adsorption: specific surface area $=236.3 \mathrm{~m}^{2} \mathrm{~g}^{-1}$ (multipoint BET equation, $R^{2}=0.998$ ), total pore volume $=0.06 \mathrm{~cm}^{3} \mathrm{~g}^{-1}$ (BJH method), and average pore size $=1.4 \mathrm{~nm}$ (BJH method). Such results reveal that specific surface area and total pore volume of the produced carbon are relatively low if compared with other carbons from agricultural residues. The surface area of apricot stones activated carbon, for instance, is $1190 \mathrm{~m}^{2} \mathrm{~g}^{-1}$ (similar to some commercial activated carbons) with total pore volume of $0.5 \mathrm{~cm}^{3} \mathrm{~g}^{-1}$ while the carbon from oat hulls has surface area ranging from 349 to $625 \mathrm{~m}^{2} \mathrm{~g}^{-1}$ with total pore volume from 84.2 to $91.4 \mathrm{~cm}^{3} \mathrm{~g}^{-1}$ [6]. However, it does not guarantee satisfactory MB adsorption. For instance, thermal treatment onto hazelnut shells activated carbon may give a high surface area of $793 \mathrm{~m}^{2} \mathrm{~g}^{-1}$ but with low maximum MB adsorption capacity at equilibrium $\left(\mathrm{q}_{\max }=8.8 \mathrm{mg} \mathrm{g}^{-1}\right)$ [8].

\subsection{Equilibrium and kinetics adsorption analysis}

The isotherm of MB adsorption onto $R$. sativus carbon shown at Fig. 2 indicates favorable adsorption of MB. Data were better described by Langmuir model $\left(\mathrm{q}_{\max }=19.8 \mathrm{mg} \mathrm{g}^{-1} ; \mathrm{R}^{2}=0.933\right)$ in comparison with Freundlich one $\left(n=13 ; R^{2}=0.852\right)$. Regarding Freundlich isotherm, the slope $1 / n$ indicates a normal Langmuir isotherm thus corroborating the homogeneous nature of the adsorbent surface also consistent with the Langmuir fit. Evaluation of the fitted separation factor $(r=0.0003)$ corroborates the statement of favorable adsorption. The maximum MB uptake capacity, $\mathrm{q}_{\max }$, was found to be comparative higher than other adsorbents from similar types of residues such as sunflower oil cake $\left(\mathrm{q}_{\max }=16.4 \mathrm{mg} \mathrm{g}^{-1}[9]\right)$, defective coffee seeds pressed cake $\left(\mathrm{q}_{\max }=14.9 \mathrm{mg} \mathrm{g}^{-1}\right.$ [10]), date pits $\left(\mathrm{q}_{\max }=12.9 \mathrm{mg} \mathrm{g}^{-1}[11]\right)$, and apricot stones $\left(\mathrm{q}_{\max }=4.1 \mathrm{mg} \mathrm{g}^{-1}[12]\right)$.

Figure 3 shows the adsorption kinetics of $\mathrm{MB}$ onto $R$. sativus carbon at changing initial $\mathrm{MB}$ concentrations. Equilibrium was attained after $12 \mathrm{~h}$ for an initial MB concentration of $100 \mathrm{mg} \mathrm{L}^{-1}$ but it did not reach the higher initial MB concentrations, even after $72 \mathrm{~h}$ adsorption. Regardless of the

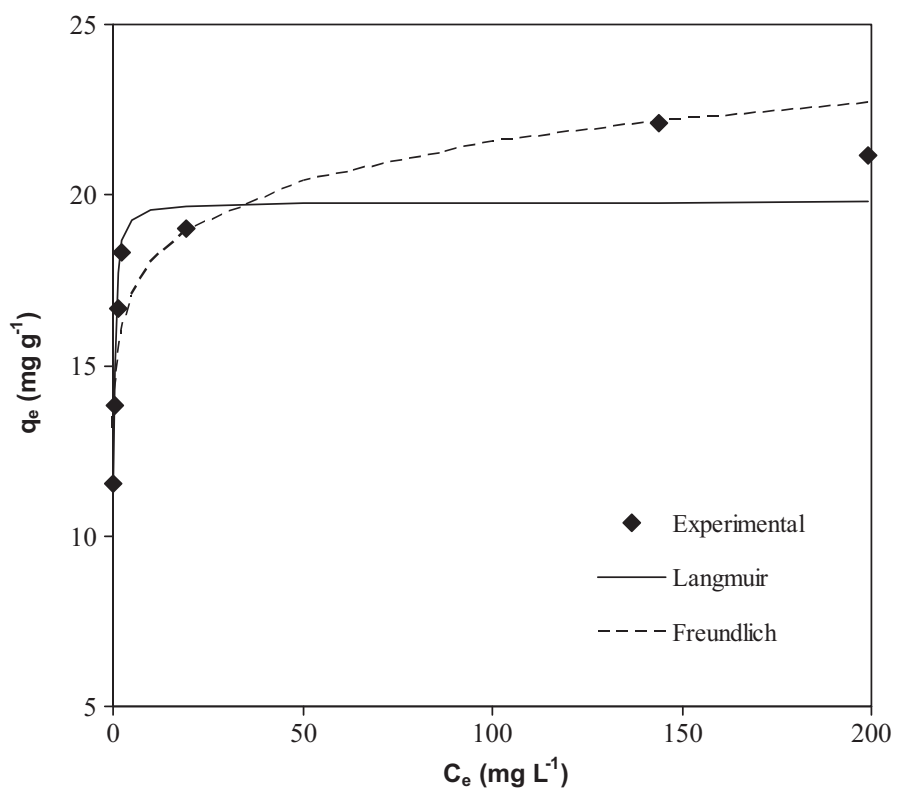

Figure 2: Adsorption isotherm of $\mathrm{MB}$ onto Raphanus sativus carbon $\left(\mathrm{t}=72 \mathrm{~h} ; \mathrm{T}=25^{\circ} \mathrm{C}\right)$. 
initial MB concentration, the adsorption process can be described by a two-stage kinetic behavior, with a rapid initial adsorption during the first $6 \mathrm{~h}$, followed by a much slower rate afterwards. A similar behavior has been reported for MB adsorption by activated date pits [11] and spent coffee grounds [13]. The faster adsorption of MB at the lower concentration indicates that adsorption occurs mainly on the surface of the adsorbent. This was expected given the measured average pore size being smaller than the size of the MB molecule, $\sim 1.5 \mathrm{~nm}$ [14]. As the initial MB concentration increases, the adsorption is separated into two phases: (i) fast adsorption resulting from the rapid attachment of the MB molecule onto the adsorbent surface; (ii) slow adsorption inside the pores [11].

According to results shown in Fig. 3, dye adsorption is strongly dependent on the initial MB concentration. An increase in the initial MB concentration from 100 to $500 \mathrm{mg} \mathrm{L}^{-1}$ resulted in a respective increase in the amount adsorbed after $72 \mathrm{~h}$ from 7.3 to $21.2 \mathrm{mg} \mathrm{g}^{-1}$. This is attributed to the increase in driving force with the increase in the initial dye concentration. However, adsorption efficiency decreased as MB initial concentrations increased as expected. An increase in the initial MB concentration from 100 to $500 \mathrm{mg} \mathrm{L}^{-1}$ led to a respective decrease in adsorption capacity from 99 to $53 \%$, indicating external surface saturation. Also, no significant differences in the amount adsorbed were observed when the initial MB concentration was raised above $300 \mathrm{mg} \mathrm{L}^{-1}$, confirming that adsorbent saturation was attained. The curves shown in Fig. 3 correspond to the pseudo second-order kinetics model fits (maximum error between estimated and experimental $\mathrm{q}_{\mathrm{e}}$ was $4 \%$ ). It can be inferred that the rate-limiting step may be chemisorption promoted by either valency forces, through sharing of electrons between adsorbent and sorbate, or covalent forces, through the exchange of electrons between the parties involved. The values of the rate constant decreased with increasing initial MB concentration, without significant differences at higher concentrations $\left(\geq 300 \mathrm{mg} \mathrm{L}^{-1}\right)$. Other models such as the irreversible first order, Elovich, Ritchie, and intraparticle diffusion provided a non-satisfactory fit for all concentrations studied as it can be seen in Table 1 .

As evidences pointed out that MB adsorption onto $R$. sativus carbon is mainly superficial, the effect of particle size was investigated at three different size fractions: $\mathrm{D}<0.425 \mathrm{~mm}, 0.425 \mathrm{~mm} \leq$ $\mathrm{D}<0.850 \mathrm{~mm}$, and $\mathrm{D} \geq 0.850 \mathrm{~mm}$. According to results shown in Fig. 4, MB uptake increases with

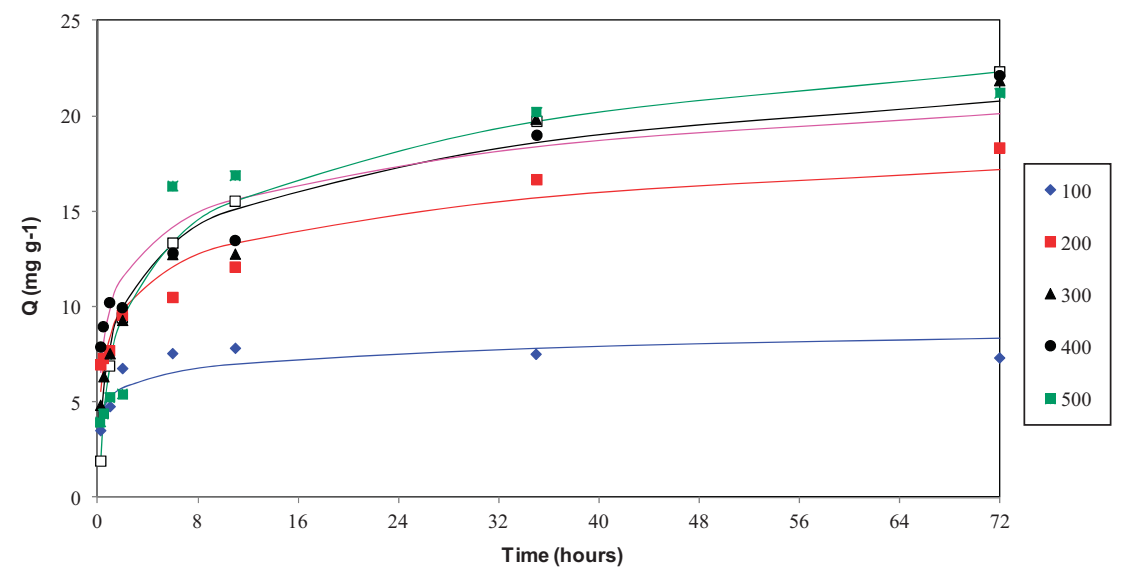

Figure 3: Adsorption kinetics of $\mathrm{MB}$ onto Raphanus sativus carbon (initial $\mathrm{pH}=5$; adsorbent dosage $=10 \mathrm{~g} \mathrm{~L}^{-1}$; temperature $=25^{\circ} \mathrm{C}$; initial MB concentration: $\bullet 100 \mathrm{mg} \mathrm{L}^{-1}, \mathbf{\square} 200 \mathrm{mg} \mathrm{L}^{-1}$, $\Delta 300 \mathrm{mg} \mathrm{L}^{-1}, 400 \mathrm{mg} \mathrm{L}^{-1}, \square 500 \mathrm{mg} \mathrm{L}^{-1}$. Solid lines correspond to the pseudo secondorder model fit. 
Table 1: Parameters fit of various kinetic models.

\begin{tabular}{lcccccc}
\hline & & \multicolumn{5}{c}{ Initial concentration (ppm) } \\
\cline { 3 - 7 } Model & Parameters & 100 & 200 & 300 & 400 & 500 \\
\hline Pseudo second-order & $\mathrm{R}^{2}$ & 0.9996 & 0.9935 & 0.9908 & 0.9890 & 0.9966 \\
& $\mathrm{k}_{2}$ & 3.04 & 0.021 & 0.014 & 0.015 & 0.015 \\
& $\mathrm{q}_{\mathrm{e}}$ & 7.35 & 18.60 & 22.41 & 22.32 & 22.03 \\
Irreversible first order & $\mathrm{R}^{2}$ & 0.9358 & 0.9933 & 0.9797 & 0.9860 & 0.9068 \\
& $\mathrm{k}_{1}$ & 1.07 & 0.0543 & 0.0579 & 0.0410 & 0.0825 \\
& $\mathrm{q}_{\mathrm{e}}$ & 5.37 & 10.98 & 15.34 & 13.17 & 14.71 \\
Elovich & $\mathrm{R}^{2}$ & 0.7625 & 0.9306 & 0.9606 & 0.9131 & 0.9136 \\
& $\mathrm{a}$ & 1955.83 & 28.62 & 4.57 & 25.82 & 1.89 \\
Ritchie & $\mathrm{a}$ & 0.72 & 2.05 & 3.01 & 2.39 & 3.59 \\
Intraparticle diffusion & $\mathrm{R}^{2}$ & 0.6020 & 0.9662 & 0.9600 & 0.9795 & 0.9845 \\
& $\mathrm{a}_{\mathrm{r}}$ & -1.21 & 0.27 & 0.27 & 0.15 & 0.58 \\
& $\mathrm{R}^{2}$ & 0.4384 & 0.9703 & 0.9477 & 0.9855 & 0.7879 \\
& $\mathrm{k}_{\mathrm{p}}$ & 0.389 & 1.489 & 2.120 & 1.761 & 2.368 \\
& $\mathrm{C}$ & 5.05 & 6.69 & 5.60 & 7.81 & 4.65 \\
\hline
\end{tabular}

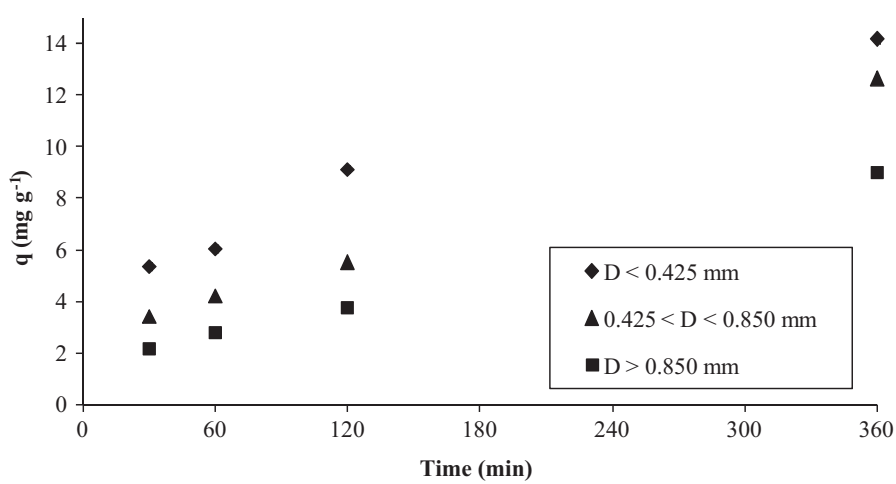

Figure 4: Effect of particle size on the MB adsorption with Raphanus sativus.

the decrease in the particle size as a result of the corresponding increase in surface area, so the use of fine fraction of carbon seems to be more appropriate to treat textile effluents.

The influence of adsorbent dosage on the efficiency of MB removal is shown in Fig. 5. The removal of MB increased with the increase in adsorbent dosage. After $24 \mathrm{~h}$, the percent removal varied from 66 to $100 \%$ with an increase in adsorbent concentration from 5 to $50 \mathrm{~g} \mathrm{~L}^{-1}$. This is due to the increase in surface area resulting from the increase in adsorbent mass. However, the amount of dye adsorbed per unit mass of adsorbent decreased with increasing adsorbent mass, as expected. 


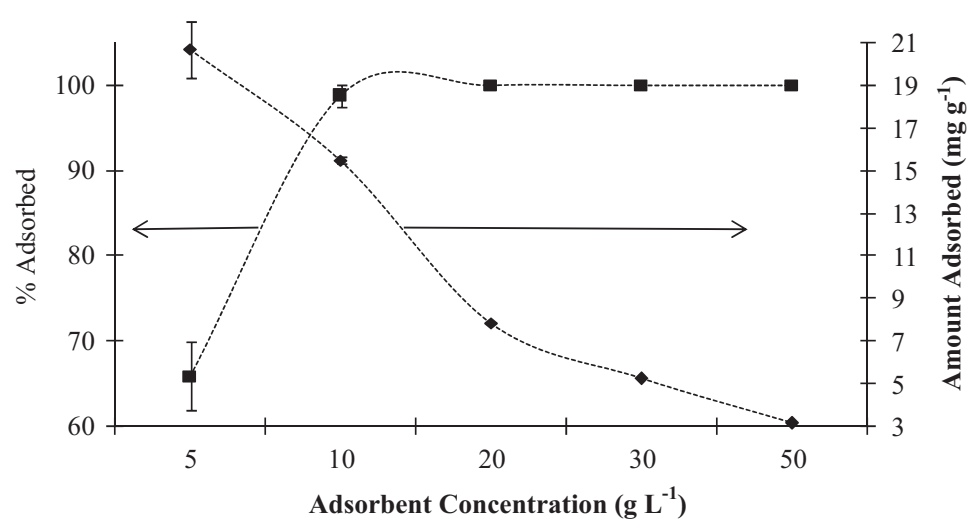

Figure 5: Effect of adsorbent dosage on the MB adsorption with Raphanus sativus.

\subsection{MB adsorption mechanism}

Raman spectra of the activated carbon of $R$. sativus before and after MB adsorption are shown in Fig. 6. Two characteristic bands which are typical of carbonaceous materials used as precursors for activated carbons were found at 1340 and $1590 \mathrm{~cm}^{-1}$ in the unloaded carbon, thus corresponding to the disorder line ( $\mathrm{D}$ band) and the graphite line ( $\mathrm{G}$ band), respectively; another characteristic band was identified at $2793 \mathrm{~cm}^{-1}$ but much softer than $\mathrm{D}$ and $\mathrm{G}$ bands. The intensity of $\mathrm{D}$ and $\mathrm{G}$ bands is an indicative of the structure of the amorphous carbon. In fact, the amount of disorganized carbons which is characterized by the intensity ratio of $\mathrm{D}$ to $\mathrm{G}$ bands (hereafter named ID/IG ratio) will affect both the pore structure and the adsorption properties of the adsorbent. The relationship between ID/ IG ratio with total BET surface area, total pore volumes, micropore volumes, mesopore volumes, and other parameters was evaluated for a number of microporous carbonaceous adsorbents prepared by oxidation of coal reject in various conditions prior to heat treatment at $600^{\circ} \mathrm{C}$ [15]. An increase on the adsorption capacity of the carbons for organic compounds with the increase of ID/IG ratio was verified. Also, higher amount of disorganized carbons (which is related to the increase on the amount of aromatic compounds in comparison with aliphatic carbons) indicates lesser space between the clusters of aromatic compounds, hence smaller micropores are obtained. According to Fig. 6, ID/ $\mathrm{IG}=1.20$ for the unloaded carbon, so pores are probably too small (microporous). Such result corroborates previous BET observations. Figure 6 also shows an intense peak in the MB-loaded curve at $480 \mathrm{~cm}^{-1}$ as well as other less intense peaks that are related to the adsorption of MB.

In order to evaluate how MB molecules are adsorbed in the $R$. sativus carbon and also to identify the predominant adsorption mechanism involved in this separation, the MB-loaded carbon spectra was subtracted from the unloaded carbon spectra. A comparison between this curve and that of solid MB spectra is shown in Fig. 7, corresponding to Raman shift interval of 200 to $700 \mathrm{~cm}^{-1}$. Figures referring to Raman shift intervals higher than $700 \mathrm{~cm}^{-1}$ are given elsewhere [6].

The bands at 448,480 , and $500 \mathrm{~cm}^{-1}$ are associated with the aggregation state of the MB molecules that might change due to the contact with the carbon surface or even with $\mathrm{pH}$ of the aqueous solution [16]. The presence of dimer-MB species is evidenced by peaks around 448 and $500 \mathrm{~cm}^{-1}$ while the monomer-MB species can be identified at $485 \mathrm{~cm}^{-1}$ ( $\delta$ (CNC) skeletal deformation mode). Therefore, MB molecules are predominantly found as dimers in the solid but they are adsorbed as monomer in the carbon. Recently, UV-VIS analysis of aqueous solutions containing MB pointed to the non-existence of dimers in the aqueous phase [17] and that change on the position and shape of 


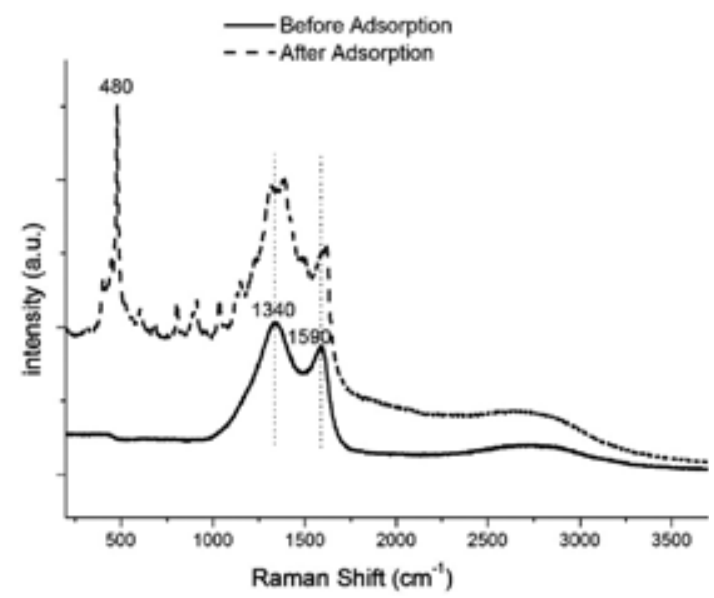

Figure 6: Raman spectra of activated carbon of Raphanus sativus before and after MB adsorption.

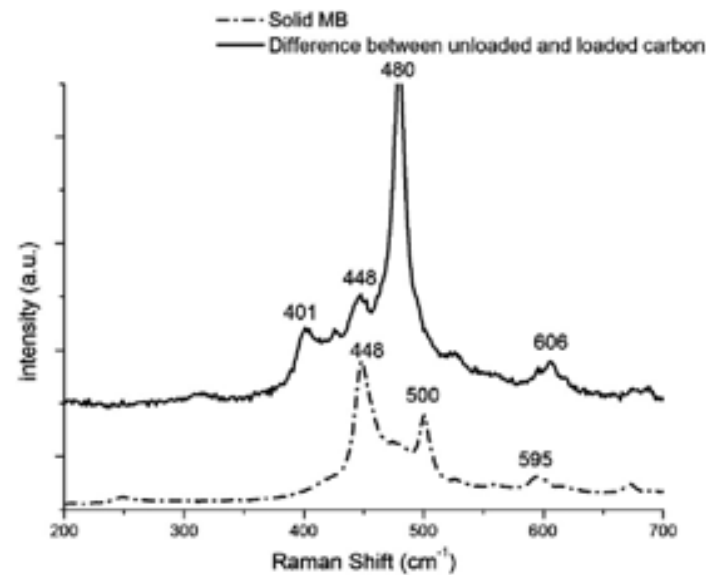

Figure 7: Raman spectra of solid $\mathrm{MB}$ and the spectra difference between unloaded and MB-loaded carbon.

bands obtained by them are in fact influenced by the ionic strength of the solution. The chemical structure of MB and its possible dimerization reaction in solution are shown in Fig. 8. The peak at $401 \mathrm{~cm}^{-1}$ can be attributed to some deformation in the C-S-C bond of the MB species [18] and no significant change in the intensity of peaks nearby $600 \mathrm{~cm}^{-1}$ was considered.

Other peaks related to vibrational modes of the molecules of solid MB and adsorbed MB are found and discussed elsewhere [6], for example, peaks related to the $\mathrm{CH}$ bond deformation $\beta(\mathrm{C}-\mathrm{H})$ at 1030 and $1151 \mathrm{~cm}^{-1}$ [19], and peak at $1038 \mathrm{~cm}^{-1}$ showing low intensity in the solid MB spectra but being quite significant when MB molecules are adsorbed in the $R$. sativus carbon. Other vibrational modes of MB molecules are related to the symmetric and asymmetric stretch of $\mathrm{C}-\mathrm{N}$ bond that are found at 1390 and $1430 \mathrm{~cm}^{-1}$, respectively [19]. The symmetric stretch of C-N bond occurs in both solid and MB-loaded carbon, but the asymmetric stretch of $\mathrm{C}-\mathrm{N}$ bond has been identified in the solid only. And finally a typical large MB peak was found at $1625 \mathrm{~cm}^{-1}$ for both spectra which is 


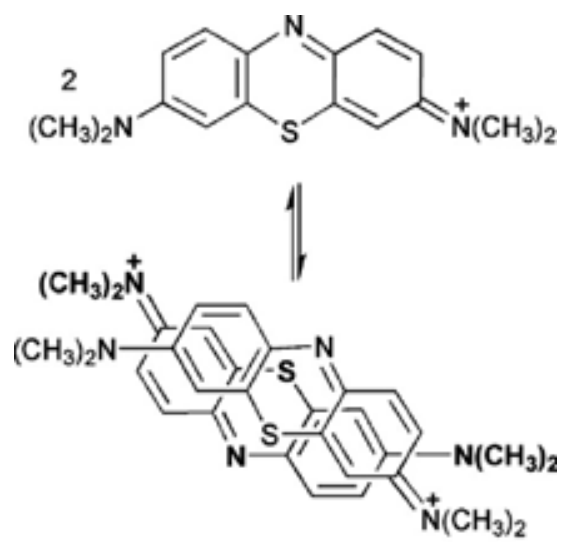

Figure 8: MB chemical structure and its possible dimer [17].

related to the $\mathrm{C}-\mathrm{C}$ bond stretch of the benzene ring of $\mathrm{MB}$ molecule $[19,20]$. It was considerably more intense in the solid MB spectra.

According to the molecule of MB shown in Fig. 8, there are three probable sites for the bond between MB and carbon: the central nitrogen atom, the central sulfur atom, and the amino nitrogen atoms. MB bonding as monomer species through the central nitrogen atom seems to be the most probable mechanism to occur during adsorption of MB molecules onto $R$. sativus carbon because a very high intensity peak at $480 \mathrm{~cm}^{-1}$ was identified, which is assigned to a $\delta$ (CNC) skeletal vibrational mode. MB bonding through the sulfur atom seems to occur because the peak near $405 \mathrm{~cm}^{-1}$, attributed to some deformation in the C-S-C bond of the MB species, has also appeared. However, bonding through an amino nitrogen atom to a carbon atom seems less probable because symmetric stretch of C-N bond at $1395 \mathrm{~cm}^{-1}$ (not shown here) seems to be not affected and the asymmetric stretch at $1430 \mathrm{~cm}^{-1}$ seems to vanish at the MB-loaded curve.

\section{CONCLUSIONS}

Experiments were conducted in order to investigate the potential of cold-pressed cake from $R$. sativus (L. Var.) seeds, a residue from biodiesel production, as a raw material for the production of carbons. It was evaluated to remove MB from aqueous solutions in order to treat textile effluents and the main results are:

- A microporous structure was found (SEM and Raman analysis) pointing out that MB adsorption occurs predominantly at the surface of the carbon (surface area $=236.3 \mathrm{~m}^{2} \mathrm{~g}^{-1}$, pore volume $=$ $0.06 \mathrm{~cm}^{3} \mathrm{~g}^{-1}$; pore size $=1.4 \mathrm{~nm}$; MB diameter $\approx 1.5 \mathrm{~nm}[21]$ ).

- Equilibrium data demonstrated favorable adsorption which was described by the Langmuir model thus indicating homogeneous adsorption. The maximum uptake capacity value $\mathrm{q}_{\max }=19.8 \mathrm{mg} \mathrm{g}^{-1}$ which is comparatively higher than other similar residue-based carbons.

- Adsorption kinetics was better described by a pseudo second-order model revealing that the ratelimiting step may be MB chemisorption promoted by either valency forces, through sharing of electrons between adsorbent and sorbate, or covalent forces, through the exchange of electrons between the parties involved.

- Adsorption probably occurs by MB bonding of monomer species through central nitrogen atom; MB bonding through sulfur atom may occur while MB bonding through amino nitrogen atom seems improbable. 
- Adsorption of MB onto carbons made of $R$. sativus seeds was predominantly superficial, so the use of finer fraction of such carbon seems to be more adequate to remove dyes from the textile wastewater.

\section{ACKNOWLEDGMENTS}

Authors are grateful to the National Institute of Science and Technology (INCT, Brazil): Mineral Resources, Water, and Biodiversity (MCT/CNPq/FNDCT/CAPES/FAPEMIG/FAPERJ/FAPESP).

\section{REFERENCES}

[1] Banat, I.M., Nigam, P., Singh, D. \& Marchant, R., Microbial decolorization of textile-dyecontaining effluents: A review, Bioresource technology, 58, pp. 217-227, 1996. doi: http:// dx.doi.org/10.1016/S0960-8524(96)00113-7

[2] Slokar, Y.M. \& Le Marechal, M.A., Methods of decoloration of textile wastewaters, Dyes Pigments, 37, pp. 335-356, 1998. doi: http://dx.doi.org/10.1016/S0143-7208(97)00075-2

[3] Robinson, T., Mcmullan, G., Marchant, R. \& Nigam, P., Remediation of dyes in textile effluent: a critical review on current treatment technologies with a proposed alternative, Bioresource technology, 77, pp. 247-255, 2001. doi: http://dx.doi.org/10.1016/S0960-8524(00)00080-8

[4] Crini, G. Non-conventional low-cost adsorbents for dye removal: a review, Bioresource technology, 97, pp. 1061-1085, 2006. doi: http://dx.doi.org/10.1016/j.biortech.2005.05.001

[5] Santos A.B., Cervantes F.J. \& van Lier J.B., Review paper on current technologies for decolourisation of textile wastewaters: Perspectives for anaerobic biotechnology. Bioresource technology, 98, pp. 2369-2385, 2007. doi: http://dx.doi.org/10.1016/j.biortech.2006.11.013

[6] Ioannidou O. \& Zabaniotou A., Agricultural residues as precursors for activated carbon production - A review, Renewable and Sustainable Energy Review, 11, pp. 1966-2005, 2007. doi: http://dx.doi.org/10.1016/j.rser.2006.03.013

[7] Lázaro D.A., Caldeira C.L, Dantas M.S.S., Franca A.S. \& Mansur M.B., Characterization of an absorbent based on Raphanus sativus (L. var.), a solid residue from the biodiesel production, for the removal of methylene blue, In: Proc. of the X Water Pollution, WIT Press, pp. 345-355, 2010.

[8] Ferrero F., Dye removal by low cost adsorbents: Hazelnut shells in comparison with wood sawdust, Journal of hazardous materials, 142, pp. 144-152, 2007. doi: http://dx.doi.org/10.1016/j. jhazmat.2006.07.072

[9] Karagöz S., Tay T., Ucar S. \& Erdem M., Activated carbons from waste biomass by sulfuric acid activation and their use on methylene blue adsorption, Bioresource technology, 99, pp. 6214-6222, 2008. doi: http://dx.doi.org/10.1016/j.biortech.2007.12.019

[10] Nunes A.A., Franca A.S. \& Oliveira L.S., Activated carbons from waste biomass: An alternative use for biodiesel production solid residues, Bioresource technology, 100, pp. 1786-1792, 2008. doi: http://dx.doi.org/10.1016/j.biortech.2008.09.032

[11] Banat F., Al-Asheh S. \& Al-Makhadmeh L., Evaluation of the use of raw and activated date pits as potential adsorbents for dye containing waters, Process Biochemical,, 39, pp. 193-202, 2003. doi: http://dx.doi.org/10.1016/S0032-9592(03)00065-7

[12] Aygun A., Yenisoy-Karakas S. \& Duman I., Production of granular activated carbon from fruit stones and nutshells and evaluation of their physical, chemical and adsorption properties, Microporous and Mesoporous Materials, 66, pp. 189-195, 2003. doi: http://dx.doi. org/10.1016/j.micromeso.2003.08.028 
[13] Franca A.S., Oliveira L.S. \& Ferreira M.A., Kinetics and equilibrium studies of methylene blue adsorption by spent coffee grounds, Desalination, 249, pp. 267-272, 2008. doi: http://dx.doi. org/10.1016/j.desal.2008.11.017

[14] Xun Y., Shu-Ping Z., Wei X., Hong-You C., Xiao-Dong D., Xin-Mei L. \& Zi-Feng, Y. Aqueous dye adsorption on ordered mesoporous carbons, Journal of colloid and interface science, $\mathbf{3 1 0}$, pp. 83-89, 2007. doi: http://dx.doi.org/10.1016/j.jcis.2007.01.069

[15] Haghseresht F., Lu G.Q. \& Whittaker A.K., Carbon structure and porosity of carbonaceous adsorbents in relation to their adsorption properties, Carbon, 37, pp. 1491-1497, 1999. doi: http://dx.doi.org/10.1016/S0008-6223(99)00012-3

[16] Rubim J.C., Sousa M.H., Silva J.C.O. \& Tourinho F.A., Raman spectroscopy as a powerful technique in the characterization of ferrofluids, Brazilian Journal of Physics, 31, pp. 402-408, 2001. doi: http://dx.doi.org/10.1590/S0103-97332001000300010

[17] Tafulo P.A.R., Queirós R.B. \& González-Aguilar G., On the 'concentration-driven' methylene blue dimerization. Spectrochimica Acta Part A, 73, pp. 295-300, 2009. doi: http://dx.doi. org/10.1016/j.saa.2009.02.033

[18] Tognalli G.N., Fainstai A., Vericat C., Vela M.R. \& Salvarezza R.C., An exploring threedimensional nanosystems with Raman spectroscopy: methylene blue adsorbed on thiol and sulfur monolayers on gold, journal of physical chemistry. B, 110, pp. 354-360, 2006.

[19] Naujok R.R., Robert V.D. \& Corn R.M., Fluorescence and Fourier transform surface-enhanced raman scattering measurements of methylene blue adsorbed onto a sulfur-modified gold electrode, Langmuir, 9, pp. 1771-1774, 1993. doi: http://dx.doi.org/10.1021/la00031a026

[20] Hutchinson K. \& Hester R.E., Raman spectroscopic studies of a thionine-modified electrode, Journal of Chemical Society-Faraday Transactions I, 80, pp. 2053-2071, 1984. doi: http:// dx.doi.org/10.1039/f19848002053

[21] Xun Y., Shu-Ping Z., Wei X., Hong-You C., Xiao-Dong D., Xin-Mei L. \& Zi-Feng Y., Aqueous dye adsorption on ordered mesoporous carbons, Journal of colloid and interface science, $\mathbf{3 1 0}$, pp. 83-89, 2007. doi: http://dx.doi.org/10.1016/j.jcis.2007.01.069 